\title{
An Analysis of the Concept of Competence in Nursing Education
}

Adrian Paul Scanlon*

ACCEPT, Waterford Mental Health Services, Ireland

*Corresponding author: Adrian Paul Scanlon, ACCEPT, Waterford Mental Health Services, Ireland, Tel: 051355419; E-mail: adrian.scanlon@hse.ie

Received date: December 14, 2017; Accepted date: December 27, 2017; Published date: December 29, 2017

Copyright: (C) 2017 Scanlon AP, This is an open-access article distributed under the terms of the Creative Commons Attribution License, which permits unrestricted use, distribution, and reproduction in any medium, provided the original author and source are credited.

\section{Abstract}

Aim: The purpose of this paper is to present an analysis of the concept of competence of nurses and examine how competence is currently measured.

Background: Nurse Education curricula have adopted a competency based model without clear and unequivocal understanding of the meaning of competence. Competence is reported to be developed incrementally and individually situated in a binary definition, these two positions have lead to confusion within nursing practice and nurse education.

Method: A literature search was conducted using various databases, including CINAHL, MEDLINE, OVID, Psych info and The Cochrane Library between 1980 and 2006. The purposes of the concept analysis are: 1) to establish a better understanding of the concept of competence as applied to nursing practice and nurse education, and 2) provide the impetus to explore empirically the competence based methods of learning in nursing education. Concept analysis described by Walker and Avant was used to examine the concept of competence.

Findings: The use of concept analysis resulted in the identification of four critical attributes in relation to the concept of competence as applied to nursing practice. The concept analysis revealed difficulty in identifying a clear meaning of the constituents of competence and the definitions assigned to a competent nurse. The four critical attributes were 'state of being', 'condition of being capable', 'sufficient for the purpose' and 'required ability'.

Conclusion: This paper provides an explanation of competence in relation to nursing practice. This explanation identifies that a nurse can be competent when the nurse is fit, adequately qualified, has the required ability, is safe to practice, capable and can function independently and proficiently as a registered practitioner.

Keywords: Concept analysis; Competence; Practice; Nurse education

\section{Introduction}

The assessment of a student nurse's clinical efficiency is measured by the achievement of a performance criteria formed within domains of competence. In the opinion of the author this notion is fundamentally flawed by the interpretation of competence and what constitutes competence. The Nursing and Midwifery Board of Ireland; the body regulating and governing nursing practice in Ireland define competence as "a complex multi-dimensional phenomenon and is defined as the ability of the registered nurse to practice safely and effectively, fulfilling his/her professional responsibility within his/her scope of practice" (The Nursing and Midwifery Board of Ireland $(\mathrm{NMBI}))[1,2]$. In relation to governing the practice of registered and professional nurses this statement is perfectly feasible and appropriate, however the difficulty arises when utilising the notion of competence to measure the development of clinical ability of student nurses.

Based on the competence statement in Competence Assessment Tool (NMBI), a nursing student has to reach a level of competence in five domains [3]. These domains consist of Professional and ethical practice, Personal and professional development, Organisation and management of care, Interpersonal relationships and Holistic approaches to care and the integration of knowledge. The document states "All five Domains of Competence represent the level the
Candidate Nurse must reach on completion of the adaptation period for entry to the register held by NMBI. The aim is to ensure that the Candidate Nurse acquires the skills of critical analysis, problemsolving, decision-making, reflective skills and abilities essential to the art and science of nursing. Safe and effective practice requires a sound underpinning of theoretical knowledge that informs practice and is in turn informed by that practice. Within a complex and changing healthcare environment it is essential that the best available evidence inform practice. This is reflected in the competencies"(NMBI).

This issue is so fundamental that the philosophical assumptions informing the notion of domains of competence, theoretical framework, assessment methods, and supervisor's role are profoundly undermined due to the ambiguity in relation to the understanding of competence. This ambiguity is manifested by the philosophical debate centred on how and when a nurse is deemed competent [4]. The fundamental question that informs this paper therefore is; can nurses develop competence incrementally? The paper also aims to explode the myth of competency-based assessment by examining the available literature and by utilising a concept analysis approach as described by Walker and Avant [5]. Various methods have been used to examine concepts [6,7]. The method selected is well-established research and scholarly literature and it is methodical and thorough. 


\section{Concept Analysis}

Walker and Avant define concept analysis as a strategy to examine the attributes or characteristics of a concept. Walker and Avant point out that a conceptual analysis should never be seen as a finished product. The aim is to capture the current definition of the concept. The process is deliberate and methodical and seeks to clarify defining and irrelevant attributes of the concept. The objective of this concept analysis fits quite neatly into afore mentioned criteria; that is to clarify the ambiguity between the understanding of competence as applied to nurse education and nursing practice.

The steps of concept analysis as described by Walker and Avant are as follows:

- Select a concept.

- Determine the aims or purposes of the analysis.

- Identify all the uses of the concept that you can discover.

- Determine the defining attributes.

- Construct a model case.

- Construct borderline, related, contrary, invented and illegitimate cases.

- Identify antecedents and consequences.

- Define empirical referents.

In relation to this analysis the selection of the concept and the aims of the study are previously defined in the introductory section of the paper. The steps three to eight will be discussed and form the structure of the analysis.

\section{Identify all Uses of the Concept}

Walker and Avant maintain that during this phase of the analysis sources such as dictionaries, thesauri, available literature and discussion with colleagues should be utilised. This process is performed to identify as many uses of the concept as possible.

\section{Dictionary definitions}

The 9th edition of the Concise Oxford Dictionary of current English and the 2nd edition of the Dictionary of the English Language were consulted in order to define competent, competence and competency $[8,9]$.

\section{Competent as an adjective}

- 1a. Adequately qualified or capable (not competent to drive). b. Effective (a competent batsman). 2. Law (of a judge, court or witness) legally qualified or qualifying. (The Concise Oxford Dictionary of current English).

- 1. Having sufficient skill, knowledge, etc; capable. 2. Suitable for the purpose: a competent answer. 3. Law (of a witness, etc) having legal capacity; qualified to testify, etc. (Dictionary of English Language).

\section{Competent as a postpositive}

- Belonging as a right appropriate (Dictionary of English language).

\section{Competently as an adverb}

- Be fit or proper (The Concise Oxford Dictionary of current English).

\section{Competence as a noun}

- The Concise Oxford English Dictionary of current English defines competence and competency: 1.a. Ability; the state of being competent. b. an area in which a person is competent; a skill. 2. An income large enough to live on, usu. unearned. 3. Law the legal capacity (of a court, magistrate, etc) to deal with a matter.

- The Dictionary of English Language defines the nouns competence and competency separately:

\section{Competence:}

- The condition of being capable.

- A sufficient income to live on.

- The state of being legally competent or qualified. Embryol. The ability of the embryonic tissues to react to external conditions in a way that influences subsequent development (Dictionary of English Language).

\section{Competency: + cies.}

- Law; capacity to testify in a court of law; eligibility to be sworn.

- A less common word for competence (Dictionary of English Language).

\section{Thesauri}

The Cassell Thesaurus and the Roget's Thesaurus of English Words and phrases were consulted $[10,11]$. These texts provided detailed explanations of words and alternatives. The following are examples of alternative terms used for competent and competence:

\section{Competent (adjective)}

- Powerful, knowing, sufficient, useful, expert, skilful, authoritative, legal, jurisdictional (Roget's Thesaurus of English words and phrases).

- Qualified, capable, able, adept, appropriate, capable, clever, fit, knowledgeable, prepared, proficient, qualified, skilled, suitable. Antonyms; incompetent, unsuitable. (sufficient, adequate) acceptable, adequate, equal, satisfactory, sufficient. Antonyms; inadequate, insufficient (The Cassell Thesaurus).

\section{Competence (noun)}

Ability, sufficiency, skill, independence, wealth, jurisdiction (Roget's Thesaurus of English words and phrases).

\section{Hermeneutic analysis}

The Oxford Dictionary defines competent as having the required ability, knowledge or authority and being effective. This and previous definitions have significant implication for the accurate and unequivocal understanding and application of the word competent. This understanding is paramount when defining the capabilities of students and qualified professional nurses. The words "required ability" implies that the individual is competent for a purpose and the purpose is defined by all nursing governing bodies as being professional and to practice safely and effectively as a professional practitioner. Therefore utilising the definitions outlined previously and applying these definitions to practice it presents an unequivocal and definitive threshold; this threshold has to be when the nurse is fit, adequately qualified, has the required ability, is safe to practice, capable and can function independently and proficiently as a registered practitioner. 
This threshold is when the governing body regulates the individual qualified to discharge his or her professional responsibility safely and effectively.

Differing opinions have been proffered to explain or define competence and little consensus gained $[12,13]$. Yet nursing education seems to persist in utilising the competency based assessment to assess clinical practice development. How nurses measure development of clinical skills is in a transition phase. This transition is from a model of clinical education informed primarily by a socialization process, to the current situation where by the primary source of education is academic augmented by a degree of clinical exposure at different levels of participation.

There seems to be a dichotomy in relation to the application of the meaning assigned to competence or competencies. This dichotomy is manifested in the meaning assigned to competent to practice and a level of competence developing through a training programme to attain a competent status. Eraut described competence as a person's overall capacity and competency refers to certain capabilities and these competencies are comprised of knowledge, skills and attitudes [14]. The notion of competencies are not clearly defined or unambiguously explained. Competent is person related and specific; competence on the contrary refers to a state assigned to an individual. Eraut defines competence accurately; however the confusion arises between accurately defining and the meaning assigned to competent, competence and competencies. What is clearly defined and unequivocal is that a nurse is competent or not competent as this is person specific and defines an individual that is legally qualified, fit for the purpose and able to perform his or her nursing role. The World Health Organisation describe competence as requiring knowledge, appropriate attitudes and observable mechanical or intellectual skills for the delivery of a professional service [15].

Eraut defines two types of competence and argues 'socially defined competence' is the ability to perform the delegated tasks to an defined standard; 'individually situated competence' alternatively is an underlying characteristic of an individual that is related to effective performance in a job situation [16].

\section{Word usage}

The end product of any nurse education programme is to produce a skilled practitioner able to provide optimal care to patients who in turn receive a high level of care. In relation to qualified, registered and skilled practitioners this provision of care can be administered by competent nurses. The Nursing and Midwifery Board of Ireland (NMBI) describe competence as being an ability to practice safely within his or her scope of practice. The scope of professional practice (NMBI) describes competence as being a transient state and that to maintain competence requires new knowledge. The requirement for continued professional development is as a result of the systems changes and nursing epistemological changes. Nurses therefore need to continually update to remain competent within their role. The Australian Nursing Council describe competence as comprising components and attributes of a person that results in the ability to be effective and superior in their performance [17]. Some of the confusion in relation to the notion of competence lies with the difficulty of definition. Competence can be described as a number of stages, a level of a continuum or a state. The United Kingdom Central Council for Nursing (UKCC) defines competence as a state i.e., one is either competent or one is not, defined by occupational standards [18]. The American Nurses Association describes a nursing competency programme to assess and determine licensure to practice. This competency assessment is based on assessment throughout a continuum of care benchmarked against common standards of nursing practice [19]. This binary definition of a competent practitioner is universally accepted and an entirely appropriate description of a qualified nurse. Competence is also measured by maintaining a standard of competency based on standards of care. The threshold for a nurse to achieve a level of competent practice varies. Benner would argue that a newly registered practitioner becomes competent only with a degree of exposure to that role 2 to 3 years after the point of registration [20]. However, as discussed previously it is entirely acceptable to suppose a person becomes a competent nurse at the level of registration [21].

\section{Pre-registration competency}

The major issue in relation to competency based assessment within an academic programme lies with the fundamental premise that informs the concept of competence. This concept varies as do the definitions that inform the notion of competence. The Nursing and Midwifery Board of Ireland defines competence within parameters defined by focus groups commissioned to analyse the concept. The working definition used by The Nursing and Midwifery Board of Ireland is also based on the works of and a consensus definition was achieved [22-25]. However, with an issue so fundamental and the application of tools of assessment so diverse as a result, the definition needs to be more definitive and unequivocal.

The Nursing and Midwifery Board of Ireland for example refer to the competency standards and state "a competency domain represents an area in which a nurse must demonstrate expertise and proficiency" (The Nursing and Midwifery Board of Ireland). If a student nurse is expected to attain a level of performance in any nursing activity or role to the level of expert this is entirely unrealistic and requires further examination.

The problem of definition therefore is manifest within the structure of clinical assessment due to the fundamental dichotomy of meaning in relation to competence. For example, the notion of a learner nurse achieving a level of expert is unrealistic and a dangerous assumption. Benner defines an incremental progression of nursing proficiency from a novice level to an expert. This progression identifies competence at level three and argues that a nurse only becomes competent at a stage beyond registration. English argued that students on the Project 2000 training programme in the UK became competent upon completing their branch programme [26]. Girot states competency is an ability to perform adequately in routine situations. The implication of this is that if extraordinary situations arise the nurse is unable to cope. However, this relates to a nurse who has attained a level of functioning and has been exposed to clinical practice at the level of registered practitioner.

The Nursing and Midwifery Board of Ireland state in the document Requirement and standards for nurse registration "student nurses are deemed to be competent or not and where competence has not been achieved the student nurse will be given opportunities to develop competence". They further qualify this statement by stating that measurement of competence is subjective i.e. "there are no ratings in the verification of competence". It is fair to assume then that a student nurse cannot be described as competent in any sense and the competencies ascribed to that individual cannot be so ascribed (The Nursing and Midwifery Board of Ireland). 


\section{Post registration competency}

As implied in dictionary definitions the meaning of competence identifies a state of being sufficient for the purpose. The competent nurse can be said to be competent for the purpose of providing nursing care. Bradshaw argues that because nursing practice has become indistinct the purpose of nursing practice has also become difficult to define [27]. The result of this undetermined purpose is that if nurses are to be competent they need to be sure what the purpose of that competency. Nurses and nursing practice has been described as an application of academic development in clinical practice or "knowledgeable doer" (Benner). Bradshaw maintains that the nursing profession needs to further define the purpose of nursing, to be able to clearly and unequivocally define what a competent nurse is, how this competency manifests itself and what form these competencies take.

\section{Empirics in relation to competence}

Assessment and definition of competence has been a persistent feature of nurse education for the last few decades. Studies in relation to competence have however been few and far between. As stated previously a consensus in relation to the definition of competence has not been achieved and therefore research questions framed in relation to competence have also been difficult to define. Girot studies ten experiences ward sisters phenomenologically [28]. This study identified attributes of competence ascribed to individuals subjectively. Equally the study identified attributes ascribed that were defined as non-competent. The study therefore identified competence as a state of being and a binary scale i.e., competent or not competent. However some of the participants of the study were unable to state how competence was measured. The study described this as tacit knowledge as described by Polanyi, where "We know more than we can tell" [29].

Ashworth and Morrison describe competence as more complex than merely ascribed attributes and a binary definition [30]. They cite the example of a nurse whose communication skills are effective within a range of spheres and the nurse who is now however delegates the task to a person who is. The conclusion is both nurses are competent however if competence is individual attributes only the former is competent. The conclusion is therefore how can educators' ascribe to a competence based curriculum of learning if development of competence is individualistic.

Learner nurses are described in the current nursing curriculum as competent to a certain level. Ashworth and Morrison dispute this ascertain on two grounds:

- Sometimes the level of ability the learner must achieve is not indicated clearly.

- Sometimes there is confusion between one level of competence and the interrelationship with other levels and other competencies.

Short examined the confusion in relation to defining competence and concluded that this confusion was a result of assuming that competence was a "descriptive concept rather than a normative concept and its referent a thing or an activity rather than a quality or state of being" [31]. He further identified four normative conceptualisations of competence:

- Performance may be measures for competence regarding specific behaviours.

- Competence can be viewed as having command of pertinent knowledge and / or skills.
- Competence may be seen as indicative of a degree of capability deemed sufficient in a particular activity.

- Finally a holistic conceptualization of competence includes knowledge, skills, attitudes, performances and levels of sufficiency.

The conclusion he reached however was that the notion of competence as not appropriate for the task it was intended. This conclusion was informed by the difficulty in extrapolating meaning due to the various connotations of competence.

The difficulty in the application of meaning in relation to competence is further confused by the way nurses are educated or trained. Traditionally nurses have been 'trained' to fulfil a role with the purpose to care for patients. As stated previously this process in undergoing transition and part of this process is a move to 'educate' nurses. Milligan argues that the debate surrounding competence is merely a debate about education and the relationship with training [32]. He compares traditional nurse education with the current National Vocational Qualification (NVQ) style training and the notion that competence is the accumulation of skills informed by knowledge and attitudes. He further describes the current nursing curricula as an educational process and describes the need to incorporate the two approaches: however he concedes the dichotomous relationship between training and education is mutually exclusive. One interesting and significant questions postulated by Milligan related to redesigning nurse education; the question being what kind of practitioners are being constructed by the educational process? Is it creating durable unquestioning workers or is it creating questioning, critical thinking individuals and how is competence measured? Freire one of the modern philosophers said educational is political, but training merely prepares individuals for a specific purpose [33]. Milligan argues that good nurse education facilitates the examination of knowledge relevant to practice that result in competence.

The link between performance and competence has been explored again with little consensus of opinion [34-37]. Runciman views competence and performance as a psychological construct and is evident through a person's competent performance. However Miller et al., identify competence as a psychological construct of skills and performance as ability. Girot's study was at variance with Miller et al., noting that performance and competence were mutually exclusive rather than inter-related. The conclusion reached in the literature is no more enlightening that nay consensus in relation to competence per se.

\section{Determine the Defining Attributes}

The previous phase identified the concept of competence in as many uses as possible and the debate surrounding its use. Many of the scholars, philosophers, educationalists and practitioners have examined the concept (indeed it is described as being an over defined rather than ill-defined concept however clarification remains illusive. Having clarified uses of the concept, repeated characteristics have been identified and these are referred to as defining or critical attributes. The following are identified as consistent defining attributes of competence:

State of being: The literature describes competence as a state and being competent as a momentary position that changes as time progresses. Therefore being described as competent achieves little, as competence is transient and dependent upon achieving a standard that may be superseded at a future stage. This notion of competence is particularly relevant to nursing, as a competent nurse would be a nurse who continually develops and seeks to apply the acquired knowledge. Benner's assertion, supported by Wooley that a competent nurse would 
be an individual who attains certain performance criteria, measured throughout an educational process and then exposed to the application of the acquired skills and knowledge appears well founded. However given therefore mentioned debate in relation to clarity and confusion, the assumption is based on the definitive meaning and purpose being identified in relation to nursing.

Condition of being capable: The UKCC described the need to produce practitioners who are fit for the purpose and fit for award [38]. However as stated by Storey educational programmes within third level institutions are designed for academic purpose and to produce graduates who have the capability to become competent practitioners [39]. The confusion is perpetuated by the distinction between occupational standards and the attainment of academic studies. The nursing profession has moved to embrace academic studies however it has amalgamated this with the inclusion of occupational standards within the learning environment. The distinction between education and training being markedly different. As Freire stated, the educational is political, but training has little more purpose than to prepare workers for the current context. One cannot by any manner of means describe a student nurse as being fit for any other purpose than that of a learner. The use of a competency based approach assumes fit for purpose at pre-determined levels, dependent upon subjective assessment; the author would contend this is a highly inappropriate and dangerous superstition.

Sufficient for purpose: As stated previously this attribute is relatively clearly defined. A person is described as competent when fit for purpose. However two issues arise; firstly competence has two definitions, in some quarters competence is seen as an absolute and is viewed by some as relative. However the relativity is accepted as being a continuum of knowing. Competence lies within a continuum between knowing how to do something and knowing how to do something very well. The second issue is as previously stated the purpose of nursing has become more obscure.

Required ability: On the surface to have requisite ability seems a fairly clear and unambiguous notion. However this statement is complicated by the interdependent duality ie to have the required ability necessitates a clear understanding of what the ability is required for and what level of ability is required and how these interrelate. Butler defines competence as an ability to meet or surpass prevailing standards of a particular activity. This implies that (1) there is more than one level of competence and (2) one may be competent at one activity and not competent at another. The problem of definition is that nursing is for more complex and multifaceted to make a blanket judgement in relation to competence and the required ability needs to be far better defined.

Having identified the themes emerging from the literature and the application of the concept in practice it reinforces the above attributes. Having reflected on the attributes it appears clear that a binary definition of competence, one that refers to a state that is transient and dependent upon capability and ability is appropriate. In addition, competence is a state applicable to the person, it has to be role specific and it has to achieve a purpose or be 'fit for purpose'.

\section{Construct a Model Case}

Walker and Avant describe a model case as a real life example of the concept including all the critical attributes and no attributes of any other concept. "Individual practitioners at the point of registration will have achieved specific learning outcomes and are accountable for their practice, regardless of any support system”(UKCC) [40]. “Competence can only be maintained by continuing education and professional development" (UKCC). The two elements combined equate to the complete notion of competence and fulfil all the critical attributes; however no single case in isolation meets the required critical attributes in practice. This illustrates to the author that to some extend the notion of competence is aspirational.

These statements illustrate the expectations in relation to the requirements for the purpose of nursing and have all the critical attributes. However the onus is then placed upon the governing bodies to provide a means of measuring competence. This notion illustrates quite clearly that competence is individually situated, measurement is subjective and "only the client can truly judge competency" [41].

\section{Construct Additional Cases}

The identification of additional cases seeks to state examples of not the concept, hence providing a clearer example of the concept under investigation (Walker and Avant).

\section{Borderline Cases}

Borderline cases are examples of the concept with some of the critical attributes, but not all of them. The following case is an example of a borderline case:

"In the early 1990's, after a career break, I returned to nursing as a ward staff nurse. A college-based nursing up-dating course had enabled me to think and write analytically and academically but left me unsure about my competence in the practicalities of caring for patients, such as using a syringe driver, measuring blood sugar or dressing a wound. Gradually I realised that I had no idea whether I was competent in the new techniques and technology which I was expected to use"(Bradshaw).

In relation to the critical attributes, the case illustrates that the nurse involved does not have a clear understanding of the required ability in relation to identifying competence, although as far as the regulating body is concerned she displays all the academic requirements to perform her duties. Therefore the nurse has abilities that may or may not be the required abilities as the case demonstrates the ambiguity in relation to what is required. The nurse is also vague about the purpose of the techniques she is supposed to be competent in, for example, she does not know if nursing is a technology based or academically driven occupation or whether it is more important to engage in caring activities to alleviate suffering or both. This case illustrates that the nurse is deficient in two of the critical attributes relating to competence.

\section{Related Cases}

Walker and Avant describe related cases as examples closely related to the concept under examination, but they do not contain the critical attributes. In identifying a concept that is closely related to competence but without the critical attributes, the author returned to Roget's Thesaurus of English words and phrases. Closely related concepts of competence that were identified included powerful, authoritative, expert, knowing, prepared, and proficient. In relation to the critical attributes identified to describe competence all of these have aspects of the critical attributes in some form. It is therefore difficult to identify a closely related concept relating to competence that could not be described as competence or form some part of competence. 


\section{Contrary cases}

Contrary cases are examples of 'clearly not the concept' under investigation Walker and Avant. The author feels it may be unfair and possibly open to legal argument to cite a particular example of an individual defined with not competence or without any of the critical attributes of competence. Such an individual should be referred to a fitness to practice aspect of the nursing regulating body for that jurisdiction. Suffice to say that any individual exhibiting none of the critical attributes would be deemed incompetent to practice in nursing.

\section{Illegitimate and invented cases}

An illegitimate case is a case that demonstrates the improper use of the concept as viewed in this investigation [5]. Competence is a global term that has grown to mean a range of definitions in a number of fields of interpretation. This paper relates competence to nursing and the notion of 'nursing competency' as defined by numerous bodies regulating nursing throughout the world. However competence also relates to a persons' legal capacity or a legally qualified person [8]. A persons' competence under these circumstances is determined by the judicial system and a decision on ability to present legal argument is decided by the courts. This is related to the nursing scenario through the notion of determination of ability, however the ability in law is far more clearly defined and the purpose clearly identified. The competence definition is made at a particular time and is a statement of competence that may alter as the person's circumstances change. However definition of such a case would not enlighten the debate in relation to competence in nursing practice as constructing a case that has no relevance to the context being investigated would have little benefit.

\section{Identify Antecedents and Consequences}

Antecedents are events that must happen before competence can be attained and consequences are those events that occur as a result of competence. It is worthwhile noting that Walker and Avant stated that a criterion cannot be both an attribute and an antecedent.

Events that must occur for an individual to be described as competent include the recognition by others, including professional bodies that an individual is educated to a particular level and is measured by defined standards. This measurement must by an ongoing process to ensure competence is maintained.

Consequences of competence include a professional and skilful individual that has the ability and is fit for the purpose. However as described previously the purpose is not clearly defined and therefore the consequences of competence are equally spurious.

\section{Define Empirical Referents}

The definition of empirical referents is the final step of concept analysis. Very often the critical attributes are identified as the empirical referents [5]. They also point out that if the concept being analysed is imprecise then the critical attributes may be equally nebulous. The abstract character of the concept of competence and the qualitative nature of the critical attributes indicates that the exploration of the concept needs to reflect this and utilise qualitative methods. The concept however needs to be clearly articulated prior to utilising the competence model without clear understanding of the notion of competence.

\section{Conclusion}

The use of Walker and Avant's method of concept analysis resulted in the identification of four critical attributes in relation to the concept of competence as applied to mental health nursing practice. This analysis served to illustrate the difficulty in identifying a clear meaning of the constituents of competence and the definitions assigned to a competent nurse. The four critical attributes were 'state of being', 'condition of being capable, 'sufficient for the purpose' and 'required ability'. In addition education and on-going measurement were identified as antecedents of competence. The consequences of competence were more difficult to measure, the effects of a lack of competence however is a clear breach of professional standards that are identified and is governed by peer regulation. The use of Walker and Avant's concept analysis is a useful first step to re-ignite the debate in relation to clearly defining competence. It also highlights the identification of nursing education and the use of training or occupational standards to measure learning.

\section{References}

1. The Nursing and Midwifery Board of Ireland (2000) Review of scope of practice for nursing and midwifery: Final report. NMBI, Dublin.

2. The Nursing and Midwifery Board of Ireland (2000) Requirements and Standards for Nurse Education programmes. NMBI, Dublin.

3. The Nursing and Midwifery Board of Ireland (2015) Competence assessment tool for nurses. NMBI, Dublin.

4. Girot EA (1993) Assessment of competence in clinical practice: A review of the literature. Nurse Educ Today 13: 83-90.

5. Walker K, Avant K (1995) Strategies for theory construction in nursing. Appleton and Lange, London.

6. Chinn PL, Kramer MK (1995) Theory and nursing: A systematic approach. Res Nurs Health 7: 73-74.

7. Rodgers BL (1989) Concepts, analysis and the development of nursing knowledge: The evolutionary cycle. J Adv Nurs 14: 330-335.

8. Thompson (1995) The concise Oxford dictionary of current English, 9th edn Oxford University Press, Oxford.

9. Collins (1986) Dictionary of English Language, 2nd edn. Collins, London

10. Kirkpatrick EM (1997) The Cassell Thesaurus. Cassell, London.

11. Kirkpatrick EM (1998) Roget's thesaurus of English words and phrases. Penguin, London.

12. Boss LA (1985) Teaching for clinical competence. Nurse Educator. 10: 8-10.

13. Butler FC (1986) The concept of competence: An operational definition. Educ Tech 7: 7-16.

14. Eraut M (1994) Developing professional knowledge and competence. The Falmer Press, London.

15. World Health Organisation (1988) Learning together to work together for health. Report of a WHO study on multi-professional education for health personnel: A team approach. World Health Organ Tech Rep Ser 769: 1-72.

16. Eraut M (2001) Keynote paper at the fifth International Conference on the regulation of nursing and midwifery. Copenhagen, Denmark.

17. Australian Nursing Council Inc (1994) National Competencies for the registered and enrolled nurse in recommended domains. Australian Nursing Council Inc, Sydney.

18. UKCC (2000) Requirements for pre-registration nursing programmes. United Kingdom Central Council for Nursing, Midwifery and Health Visiting, London.

19. American Nurses Association (2004) Nursing: Scope and standards of practice. American Nurses Association, Washington.

20. Benner P (1984) From Novice to expert: Excellence and power in clinical nursing practice. Addison Wesley, Menlo Park, California. 
Citation: Scanlon AP (2017) An Analysis of the Concept of Competence in Nursing Education. Adv Practice Nurs 2: 144. doi: 10.4172/2573-0347.1000144

Page 7 of 7

21. Wooley N (1990) Nursing diagnosis: Exploring factors which may influence the reasoning process. J Adv Nurs 15: 110-117.

22. Lenburg CB (1999) Framework, concepts and methods of the competency outcomes and performance assessment. COPA Model, New York.

23. Griffin C (2001) An bord altranais conference, development of competencies for registration, ABA, Dublin. Published on An Bord Altranais Website.

24. Wright D (1998) Promoting accountability through competency assessment, The ultimate guide to competency assessment in healthcare 2nd edn. Creative Healthcare Management, Minneapolis MN.

25. Del Bueno DJ (1995) Why can’t new grads think like nurses? Nurse Educator 19: 9-11.

26. English I (1993) Intuition as a function of the expert nurse: A critique of Benner's novice to expert model. J Adv Nurs 18: 377-393.

27. Bradshaw A (2000) Editorial. J Clinical Nurs 9: 319-320.

28. Girot EA (1993) Assessing competence in clinical practice: A phenomenological approach. J Adv Nurs. 18: 114-119.

29. Polanyi M (1966) The tacit dimension. Routledge and Kegan Paul, London.

30. Ashworth P, Morrison P (1991) Problems of competence-based nurse education. Nurse EducToday. 11: 256-260.

31. Short EC (1984) Competence re-examined. Educ Theory 34: 201-207.

32. Milligan F (1998) Defining and assessing competence: The distraction of outcomes and the importance of educational process. Nurse Educ Today 18: $273-280$.
33. Freire P (1985) Pedagogy of the oppressed. Pelican, Suffolk.

34. While AE (1994) Competence versus performance: Which is more important? J Adv Nurs 20: 525-531.

35. Medley DM (1984) Teacher competency testing and the teacher educator. In advances in teacher education Ablex, Norwood, New Jersey, pp. 51-94.

36. Miller C, Hoggan J, Pringle S, West G (1988) Credit where credit's due. The report of the Accreditation of the Work Based Learning Project. Scotcert, Glasgow.

37. Runciman P (1990) Competency-based education and the assessment and accreditation of work-based learning in the context of project 2000 programmes of nurse education: A literature review. The National Board for Nursing, Midwifery and Health Visiting for Scotland, Edinburgh.

38. UKCC (1999) Fitness for practice. United Kingdom Central Council for Nursing, Midwifery and Health Visiting, London.

39. Storey L (1998) Functional analysis and occupational standards: Their role in curriculum development. Nurse Educ Today 18: 3-11.

40. UKCC (1990) The report of the post registration education and practice project. United Kingdom Central Council for Nursing, Midwifery and Health Visiting, London.

41. Dolan G (2003) Assessing student nurse clinical competency: Will we ever get it right? J Clin Nurs 12: 132-141. 